\title{
LA CRÍTICA LITERARIA EN LAS REVISTAS DEL FIN DE SIGLO COMO FUENTE HISTORIOGRÁFICA
}

\author{
María Pilar Celma Valero \\ pilar@fyl.uva.es \\ Universidad de Valladolid
}

\section{Resumen}

Se hace un repaso de la crítica literaria inserta en las revistas del Fin de siglo, que adquiere una importancia inusitada en el momento, así como de las distintas modalidades críticas, para valorar su potencial utilización como fuente historiográfica en la reconstrucción de este controvertido periodo de la literatura hispánica. Los artículos de crítica objetiva resultan más útiles para apreciar la recepción de autores y obras. Los artículos de crítica subjetiva, impresionista, permiten conocer la concepción estética tanto del autor reseñado como del crítico.

Palabras clave: crítica, revistas literarias, fuente, historiografía, crítica impresionista, crítica satírica, crítica objetiva.

\begin{abstract}
An overview of literary criticism inserted into magazines Fin de siglo, which is unusually important when done as well as reviews of different modalities to evaluate their potential use as historiographical sources in the reconstruction of this controversial period Hispanic literature. Items objectively review most useful to appreciate the reception of authors and works. Items subjective, impressionistic, reviewed provide insight into the design aesthetics of both the author outlined as critical.
\end{abstract}

Keywords: criticism, literary magazines, source, historiography, impressionistic criticism, satirical criticism, objective criticism.

Anales, 26, 2014, pp. 109-126 
Pido disculpas porque voy a empezar este artículo utilizando la primera persona, con el objetivo final de demostrar, una vez más, la riqueza inagotada (Ribbans, 1958) de las revistas del Modernismo, como fuente historiográfica, para la reconstrucción del periodo que comprende los años en torno al cambio del siglo XIX al XX. Tengo una razón que aduzco como captatio benevolentiae y que espero justifique este excesivo personalismo: el día 11 de mayo de 2014 se cumplieron veinticinco años de la lectura de mi tesis doctoral en la Universidad de Salamanca. Estos años trascurridos no han hecho sino ratificar el acierto en la elección del tema, por lo que mi primer tributo de gratitud ha de ser hacia mi director de tesis, Manuel María Pérez López, y hacia el admirado y muy querido maestro Ricardo Gullón, que me sugirió el tema de las revistas literarias del Modernismo como vía para la reconstrucción de la realidad literaria de ese momento. Su libro El Modernismo visto por los modernistas fue una revelación para mí y un modelo que me guió siempre.

Mi tesis doctoral se titulaba «Aproximación al fin de siglo español a partir de la prosa crítica y de reflexión estética». En ella, primero acotaba y describía el material historiográfico que iba a utilizar como fuente (las más importantes revistas literarias entre 1888 y 1907) y después realizaba una reconstrucción de la época a partir de los materiales críticos obtenidos en el rastreo de dichas revistas. De mi tesis doctoral derivaron tres publicaciones: la monografía titulada La pluma ante el espejo (Visión autocrítica del Fin de siglo) (1989a); una antología de textos titulada La crítica de actualidad en el Fin de siglo (1989b); y, dos años después, el libro Literatura y periodismo en las revistas del Fin de siglo. Estudio e indices (1991a).

Fue este último un libro bien acogido por la crítica, ya que se consideró sumamente útil para futuras investigaciones. Se trataba del estudio de veinte revistas, publicadas entre 1888 y 1907 y del índice del contenido de todas ellas: en total recoge 30.651 entradas; más un índice onomástico. A finales de los 80 , cuando yo estaba confeccionando esos índices, la informática estaba mucho menos desarrollada que hoy en día. Así que, aunque naturalmente pude disponer de ordenador, el proceso de elaboración de los índices fue «artesanal». Es decir, por medio de fichas individuales para cada artículo y elaborando el listado completo entrada por entrada, numeradas consecutivamente hasta alcanzar las 30.651. Sí pude disponer de un programa para poder hacer de manera casi automática el índice onomástico, que recoge a todos los autores de los artículos, con la referencia del orden numérico de sus correspondientes entradas.

En estos veinticinco años la situación ha cambiado mucho. Actualmente hay ya muchas bibliotecas y hemerotecas que ofrecen sus fondos 
digitalizados (por supuesto, no todos sus fondos). En el caso de España, la institución más importante es, obviamente, la Biblioteca Nacional, que ha digitalizado ya un gran número de periódicos y revistas. (http://hemeroteca digital.bne.es). También ofrecen importantes fondos digitalizados la Biblioteca virtual de Prensa Histórica (http://prensahistorica.mcu.es), la de la Hemeroteca Municipal de Madrid (http://www.madrid.es/portales/munimadrid/ es/Inicio/Ayuntamiento/Cultura-y-Ocio/Hemeroteca-Municipal-de-Madrid? vgnextfmt=default\&vgnextoid=b8c9balb6bd7d010VgnVCM1000000b205a 0aRCRD\&vgnextchannel=0c369e242ab26010VgnVCM100000dc0ca8c0RC RD\&idCapitulo=5417693) o la Biblioteca Digital de la Comunidad de Madrid (http://www.bibliotecavirtualmadrid.org/bvmadrid_publicacion/es/estaticos/ contenido.cmd? pagina=estaticos/presentacion). Sin embargo, aunque algunas de las revistas del Modernismo han sido digitalizadas (Helios, Juventud, Electra, La España moderna...), puede afirmarse que la simple digitalización no garantiza el aprovechamiento de las revistas por los estudiosos. Pongo como ejemplo el caso de la más importante revista del Modernismo, Helios, que se encuentra en la Biblioteca Digital de la Comunidad de Madrid, pero que sólo ofrece la fotografía de cada una de sus páginas. Es cierto que evita al estudioso tener que desplazarse, pero poco más le ayuda. Cuando sólo se estudia una revista, le edición facsímil puede ser suficiente, pero si se estudia a un autor, o un tema concreto, y se quiere buscar en el fondo hemerográfico general de la época, las digitalizaciones actuales no ayudan demasiado. Si analizamos el procedimiento de búsqueda, por ejemplo, en la Hemeroteca digital de la $\mathrm{BN}$, vemos que no satisface todas las necesidades de los estudiosos, pues la búsqueda es sólo por palabras y, por tanto, no es útil para buscar por temas y, por supuesto, no contempla la posibilidad de búsqueda de imágenes. Si se busca un autor, al no separar por campos, puede dar miles de resultados, con lo que en la práctica resulta muy poco útil. Por ejemplo, si un estudioso busca artículos de la época para estudiar la recepción de un autor como Unamuno e introduce esta palabra en el buscador, le saldrán unas 50.000 entradas, sin ninguna clasificación ni guía.

En mi opinión, la edición digital tiene que ofrecer mucho más. Si se necesita un artículo, debería poderse cortar y exportar y, además, en OCR, de forma que pueda manipularse. Si se está trabajando en un solo autor, buscar con rapidez todos los artículos que él publicó en una o varias revistas. Si se está trabajando sobre la recepción de un autor u obra concretos, poder buscar las reseñas que se escribieron. Así pues, hemos avanzado mucho, pero hay que avanzar más y sacar el máximo partido a las posibilidades que hoy ofrecen las TIC: no basta la digitalización, es necesaria una gran base de datos en la que 
se pueda acotar el campo de búsqueda y se puedan, además, hacer búsquedas combinadas por varios campos. Insisto: la aportación de las nuevas tecnologías no puede ser solo la digitalización (y que veamos en una pantalla lo que antes veíamos al natural en una hemeroteca). Han de servir como instrumento para facilitar la investigación y esto solo puede conseguirse mediante potentes bases de datos.

Por otra parte, tampoco es ya necesario insistir en la importancia de las revistas como fuente historiográfica. Dos revistas de las que yo trabajé han sido objeto de tesis doctorales: Renacimiento, por Inmaculada Rodríguez Moranta (2012), y Vida Nueva, por José Bernardo San Juan. Además, se han realizado dos Congresos Internacionales, el primero en Lugo, en 2008, coordinado por Javier Serrano Alonso y Amparo de Juan Bolufer (2009); y otro, en Augsburgo, en junio de 2013, coordinado por Hanno Ehrlicher. Por último, este número especial de Anales de Literatura Española dedicado a «Revistas literarias españolas e hispanoamericanas (1869-1914)», demuestra la oportunidad de esta nueva convocatoria en torno a ellas y la fecundidad de los estudios derivados del análisis de los contenidos de dichas publicaciones.

Cierro ya este repaso a la situación del estudio de las revistas desde mi propia experiencia, manifestando que no puedo afirmar que mis estudios hayan contribuido a mejorar la situación inicial, pero sí que personalmente me han resultado muy gratificantes y que han llenado mi vida profesional durante más de veinticinco años.

Aunque la crítica literaria ha acompañado al periodismo desde su mismo origen en el siglo XVIII y se fue desarrollando con importancia creciente a lo largo del siglo XIX, el auge de la misma que se produce en torno al cambio de siglo no tiene precedentes ni casi consecuentes: apenas hay libro que se publique cuya aparición no sea reseñada en las revistas literarias del momento. Y puede afirmarse que casi todos los escritores abordan en algún momento la crítica literaria de obras ajenas: Valera, Clarín, Unamuno, Manuel Machado, Juan Ramón Jiménez, Azorín, Martínez Sierra...

Son muchas las revistas que tienen secciones fijas dedicadas a la crítica literaria: La Ilustración española y americana, además de múltiples artículos sueltos, tiene una sección fija de crítica teatral -aunque con diversos títulos-; los primeros años está a cargo de Manuel Cañete; después de Mariano de Cavia (finales 1891-92) y, luego, de Eduardo Bustillo, desde los últimos números de 1892.

En Madrid Cómico publicó Clarín sus «Paliques» desde los que, como Ribbans afirma, «semana tras semana, imponía sus severas normas, no libres de pedantería, sobre los jóvenes que iban surgiendo: les exigía sobre todo 
casticismo, estudio, humildad, y sus fallos tenían un tono categórico y definitivo» (1958: 31). Habituales fueron también los «Baturrillos», de Fray Candil. En la tercera etapa de Madrid Cómico, marcada por cierto aperturismo ideológico y, sobre todo estético, se abrieron secciones que pretendían dar a conocer la nueva literatura, tales como «Los poetas jóvenes»; «Libros recibidos», por J.M.R.; «Libros nuevos», por Gregorio Martínez Sierra; o «Vida Literaria», por Bernardo G. de Candamo.

La España Moderna tuvo primero la sección «Impresiones literarias», a cargo de Francisco Villegas (1891-1894), reemplazada luego por «Crónica literaria» de Eduardo Gómez de Baquero -a partir del número 76 de1895-; grande es la importancia de esta sección puesto que su autor, con objetivismo y desinterés poco habitual en la crítica de la época, repasa todo el panorama literario español del fin de siglo: desde los autores más viejos a los más jóvenes, en los más variados géneros y tendencias. A él me referiré luego como ejemplo de la fecundidad, rigor y acierto de este tipo de crítica.

En Revista nueva (1899) hay una sección titulada «Libros y folletos» a cargo de diversos autores (Henry D. Davray, Baroja, Enrique Corrales, Bernardo G. de Candamo y Julio Poveda). Posteriormente el título es «Libros nuevos» y firman las reseñas L. Ruiz Martín, Luis de Lara, Julio Poveda, E. Alonso y Orera, U. González Serrano, Bernardo G. de Candamo; incluso Unamuno llega a participar en esta sección, en el n. ${ }^{\circ} 15$ de la revista, comentando Redenta, de Timoteo Orbe. En algunos números aparece como sección específica «Lecturas americanas».

En las revistas creadas por la nueva generación de escritores, Helios (1903), Alma española (1904) y Renacimiento (1907), tampoco podía faltar la crítica literaria, que pretendía dar a conocer las nuevas voces. En la primera, «Los libros» quiere presentar las publicaciones recientes tanto de autores españoles, como de hispanoamericanos y europeos. Son sus autores Juan Ramón, Martínez Sierra, Pérez de Ayala, Ruiz Castillo, etc. En Alma española hay una sección llamada «La farándula» que, a cargo de Martínez Ruiz, está dedicada a comentarios literarios, especialmente de teatro, sustituida luego por «Los libros», firmada también por Martínez Ruiz. En Renacimiento, se publica la sección «Los libros», dedicada a dar cuenta de las publicaciones recientes, con breves comentarios críticos, a cargo de distintos autores: Martínez Sierra, José Francés, Miguel A. Rodenas, Luis Trigueros, etc.

En La Lectura se incluyen unas "Notas bibliográficas», a cargo casi siempre de escritores, que enjuician a otros escritores. Así, por ejemplo, Unamuno juzga España contemporánea, de Rubén Darío; Gregorio Martínez Sierra se ocupa de Salvador Rueda; Jacinto Benavente enjuicia a Martínez Sierra; 
y Juan Valera se enfrenta a una novela de José Nogales. En Electra, Ramiro de Maeztu se encarga de «Los libros y los hombres». En La República de las Letras, se atiende a «La vida literaria». Nuestro Tiempo tiene una «Revista bibliográfica»... Incluso en periódicos, como El Globo o el Heraldo de Madrid, son frecuentes breves reseñas o presentaciones de escritores.

En suma, la literatura del día tuvo un magnífico cauce de difusión en el amplio espacio dedicado por la prensa periódica a la crítica literaria. Y la buena recepción que los artículos críticos debían de obtener se demuestra en el hecho de que se publicaron diversas recopilaciones en forma de libro: así, por ejemplo, Emilio Bobadilla, Fray Candil, publicó Escaramuzas (1888), Capirotazos (1890), Triquitraques (1892), La vida intelectual I. Batiburrillo (1895), Grafómanos de América (1902), Al través de mis nervios (1884) y Muecas (1908); Antonio de Valbuena, Ripios académicos (1890), Ripios vulgares (1891), Ripios ultramarinos (1893), Des-trozos literarios (1899); Eduardo Gómez de Baquero, Letras e ideas (1905); Gregorio Martínez Sierra, Motivos (1905)...; Andrés González Blanco, tres series de Los contemporáneos (1907, 1910 y 1911); Clarín, Folletos literarios (1886-89), Mezclilla (1888), Palique (1893) y Solos de Clarín (1890-1898); etc.

Sin embargo, no todos los artículos críticos tienen el mismo valor como fuente historiográfica para reconstruir el panorama literario del Fin de siglo, sino que depende en gran medida del enfoque crítico que predomine. Lo primero que hay que señalar es que la crítica académica apenas se ocupó de la literatura coetánea, en todo caso de figuras ya consagradas; así, Menéndez Pelayo dedicó algunas páginas a Pereda, Galdós, Valera, Campoamor, Núñez de Arce, pero prácticamente ninguna atención a los jóvenes que empezaban a despuntar.

Dentro de la crítica de actualidad, publicada en la prensa, hay que considerar dos grandes bloques de modalidades críticas, según el enfoque predominante: la crítica objetiva y la crítica subjetiva. He dicho enfoque predominante, porque los límites entre una y otra no siempre son nítidos y la adscripción a una modalidad no siempre es excluyente: Clarín, por ejemplo, analiza determinados componentes de una obra con objetividad y los aduce como base para el juicio derivado, con lo que habría que adscribirlo a la crítica objetiva; pero, a la vez, él sabe que, a la hora de enjuiciar una obra, influye necesariamente el gusto personal. Clarín tiene un ideal de belleza y la valoración de una obra dependerá de su adecuación a aquél. A los que le acusan de parcialismo y de afán de imponerse, les contesta que en efecto su misión consiste en «querer imponer racionalmente lo que se tiene por verdadero» (1890: 197). En esta afirmación se resume su concepción de la crítica: la argumentación, 
en la que se apoyará el juicio final, debe estar basada en la razón, en la objetividad, pero ni la belleza ni la verdad son valores absolutos, incuestionables, sino que tienen un alto grado de subjetividad. No obstante, este margen de subjetividad dista mucho de la modalidad crítica que podemos denominar crítica subjetiva, de carácter impresionista, que va a ser la más característica del Modernismo: en ella, el crítico es casi siempre un escritor que utiliza la obra de otro escritor para, a partir de las sugerencias que ésta le brinda, hacer una valoración de la misma y, en ocasiones, una recreación literaria de temas, ambientes o cualquier otro componente de la obra original; o, simplemente, la utiliza como punto de partida para hacer una reflexión estética de carácter general.

Es obvio que la crítica subjetiva tiene un gran valor para el estudioso actual, porque ofrece de manera explícita y de primera mano la concepción estética de crítico y criticado, pero no permite conocer la recepción general de una obra. Son los artículos que plantean un enfoque objetivo los que pueden resultar más útiles a la hora de ayudar al estudioso actual en la reconstrucción historiográfica. Estudiar la recepción crítica permite contemplar los gustos estéticos de lectores y críticos y nos revela a menudo cuán diferente era la apreciación que merecieron obras y autores en su momento respecto a la consideración actual. Puede ocurrir que escritores que tuvieron un gran éxito de público (como Felipe Trigo) o merecieron un aplauso casi unánime por parte de la crítica (como Vicente Medina) gocen hoy de una consideración muy limitada y apenas sean conocidos fuera del marco académico o, en el segundo caso, fuera de la región murciana.

Dentro de la crítica objetiva se pueden establecer diversas maneras de ejercitarla. En primer lugar, tuvo mucho éxito la crítica satírica. Hubo revistas (Gedeón, Madrid Cómico, Gente vieja...) que acogieron con regocijo este tipo de crítica y dispararon sus dardos tanto hacia autores que gozaban de consideración general como hacia los jóvenes modernistas. Éstos fueron diana favorita de la crítica satírica. Puede afirmarse que los movimientos idealistas son más susceptibles de ser satirizados que aquellos otros más apegados a la realidad. Lo diferente sorprende al público medio, le resulta hilarante; le escandaliza, incluso. Recordemos la genial sátira de los románticos hecha por Mesonero Romanos. Al fondo idealista, el Modernismo añadía la marginalidad de la vida bohemia y un gusto por un lenguaje específicamente poético: en suma, los modernistas, por su aspecto (Valle-Inclán con sus largas barbas y melenas, Azorín con su paraguas rojo ...), por su vida bohemia (Alejandro Sawa...., los Machado y Gómez Carrillo en París...), su anarquismo literario, su culto a la belleza, su léxico específico (marcado por el decadentismo, el 
exotismo, el simbolismo, el impresionismo...), se convertían en un potente reclamo para burlas y parodias.

Sin duda la figura cumbre de la crítica satírica es Antonio de Valbuena, que firmó también con los seudónimos de Venancio González y Miguel de Escalada. Publicó artículos en varios periódicos y revistas: El Imparcial, Heraldo de Madrid, La Época, La Correspondencia de España, Madrid Cómico... Su crítica es bastante superficial y se concentra en ridiculizar distintos aspectos personales (incluye a veces aspectos de ideología y de orientación política) y literarios, muy especialmente fallos formales: ripios, errores gramaticales, uso inapropiado de léxico... En estos fallos, se fundamenta el juicio crítico: una obra no puede ser buena si no está bien escrita. Los dardos envenenados de Antonio de Valbuena se dirigen a menudo a escritores que gozaban de un aprecio bastante generalizado. Pongo como ejemplo esta acérrima crítica:

Dice Doña Emilia Pardo Bazán, en una Página suelta, que ni es suelta ni página, sino embutido de tres columnas muy apretado:

«El destacamento había marchado toda la mañana...»

Marchar propiamente es partir; de manera que ya no está del todo bien eso de que había marchado toda la mañana. Pero no hay que detenerse tan pronto. Sigamos la marcha literaria de Doña Emilia:

«El destacamento había marchado toda la mañana y después de un alto, fue preciso seguir la caminata emprendida para acampar, ya anochecido, como Dios dispusiese...»

¡Ah! ¿Con que como Dios dispusiese? ¿Es decir que todavía no habían acampado?... Y, entonces, ¿cómo dice Doña Emilia que al acampar estaba ya anochecido? Hubiera dicho "para acampar al anochecer» o «cuando añocheciera» o «cuando hubiera anochecido», y hubiera resultado la construcción más natural y no la [sic] hubieran hecho falta tantas comas. (Valbuena, 1897: s.p.).

La actitud de superioridad y el tono despectivo que preside este tipo de crítica, junto a la superficialidad de análisis, desvelan su falta de rigor e imparcialidad, lo que hace que tenga poco valor para el estudioso actual.

Sin llegar a los extremos de la crítica satírica, sobre todo por no centrarse sólo en aspecto formales, pero compartiendo con ella la actitud de superioridad del crítico y, en consecuencia, la intención de desprestigio del autor reseñado, se encuentra un tipo de crítica que podemos llamar «judicial». Para poder «juzgar» una obra y aportar «pruebas» que faciliten el veredicto final, se necesita que existan unas «leyes» en las que sustentar dicho dictamen. Es decir, este tipo de crítica requiere el convencimiento de que existen unos valores absolutos (verdad, belleza, bondad) a los que debe adecuarse toda obra de creación. Estos críticos pueden analizar aspectos de contenido, relacionados con la verdad o la moral, y aspectos formales, relacionados con el ideal de 
belleza. Es fácil deducir de esta caracterización dos cuestiones: primera, que es un tipo de crítica no acorde con la ideología y la estética de la generación que empieza a publicar en torno al cambio de siglo, puesto que ésta no admite esos ideales, sino que, por principio, cuestiona todo valor absoluto ${ }^{1}$; por tanto, los escritores modernistas, cuando afronten la labor crítica valorarán una obra, pero desde perspectivas muy diferentes, sabiendo que el juicio siempre es subjetivo. Segundo, que los modernistas sirvieron también de diana favorita para este tipo de crítica, no sólo por cuestiones formales (como ocurría con la crítica satírica), sino sobre todo por aspectos de contenido. En el aspecto formal se tienen en cuenta cuestiones de métrica, de usos lingüísticos, de impropiedad en la utilización de léxico, etc.; unas veces se esgrimen como prueba la inadecuación a las normas gramaticales, retóricas, métricas...; otras veces, el único criterio es el «buen gusto», como decía Clarín. Respecto al contenido, se analizan cuestiones como los ideales patrióticos, la moralidad, el respeto a la tradición, distintas virtudes (o el ataque a ellas), etc.

De la misma manera que este tipo de crítica se basa en la existencia de unos valores absolutos e incuestionables, se apoya en el convencimiento de la función didáctica de la literatura: toda obra debe, antes que procurar un placer estético, enseñar. La literatura ha de ser siempre educadora. Como antes, esta actitud dogmática y moralizadora se presenta sumamente distante de los ideales modernistas.

El principal representante de este tipo de crítica fue Clarín, que encontró en la crítica de actualidad un complemento económico, nada despreciable ${ }^{2}$, a su dedicación docente. Aunque utilizó algún otro seudónimo, fue por el de Clarín, adoptado cuando colaboraba en el periódico El solfeo, por el que fue más conocido. Colaboró en muchos periódicos y revistas, como El Imparcial, Madrid Cómico, La vida literaria... Su amplia producción como crítico fue recopilada en varios libros: Sermón perdido (1885), Folletos literarios (1886-89), Ensayos y revistas (1888-92) y Solos, de «Clarín» (1890-98). Hay que recordar que en su época obtuvo mayor fama como crítico que como narrador y que fue «el crítico más criticado», por su rigor y por su mordacidad a menudo

1. Recuérdese la proclamación del relativismo que hace Azorín en «Somos iconoclastas»: «Pero el curso del tiempo es fatal e inexorable. La vida se engendra de la muerte; no podría haber formas nuevas si las antiguas no perecieran. Y después, debemos pensar que toda labor de crítica, aun injusta, aun violenta, es preparatoria de nuevos estados que sin la crítica no existirían. Y luego hemos de convenir que no hay nada definitivo e inmutable en las cosas humanas. Lo absoluto no existe» (1904: 15-16).

2. Así lo pone en evidencia un anónimo autor, en Revista Nueva, que lo acusa de ser un pesetero (1899: 120-21).

Anales, 26, 2014, pp. 109-126 
innecesaria e hiriente ${ }^{3}$. Pero la verdad es que sus críticas tienen gracejo y es un buen lector que pone en evidencia elementos que a otros les podían pasar desapercibidos. Le falla la actitud rigurosa, paternalista y, a menudo, satírica.

La crítica de Clarín ha sido suficientemente estudiada (Beser, Martínez Cachero, Ribbans), por lo que no me voy a detener en su análisis. Quiero, no obstante, poner en evidencia su parcialidad, que queda en entredicho cuando se compara la actitud benevolente e incluso elogiosa hacia los autores del Madrid Cómico (Juan Pérez Zúñiga, Sinesio Delgado, Vital Aza...) con la inclemencia que muestra hacia otros, como Emilia Pardo Bazán o Salvador Rueda. Veamos dos ejemplos: en su crítica a Miguel Ramos Carrión, dramaturgo de cierto éxito en su momento y colaborador de Madrid Cómico, Clarín reconoce algunos defectos menores, pero se los perdona por su falta de pretensiones y por sus asumidas limitaciones. Elogia su ingenio, su fecundidad y su modestia. Y, frente al de los ídolos que defienden nuevos moldes, le augura un éxito continuado (Clarín, 1893a: 3).

Muy distinto es el artículo dedicado a Salvador Rueda (Clarín, 1893b: 3). El tono de superioridad propio de la crítica judicial se trasparenta desde el principio. Clarín adopta siempre una actitud paternalista y se permite echar «una de cal y otra de arena». Comienza ubicando a Rueda dentro de la nueva literatura (aunque en realidad pertenecen a la misma generación, pues Rueda sólo es cinco años menor que Clarín), hacia la que claramente se muestra contrario: «Salvador Rueda es de los pocos literatos jóvenes que será una lástima que se echen a perder en esta anarquía mansa de nuestras letras, donde en rigor no hay letras, pero sí hay anarquía» (Clarín, 1893b: 3). Aprovecha para denunciar los alardes reformistas de esos «muchachos», tema que va a ocupar gran parte del artículo. Alternando reproches y mesurados elogios hacia Rueda, declara lo que no le perdona: el «haberse metido a profeta de su modo de entender la poesía». El reproche va dirigido a Rueda y, con él, a todos los representantes de la nueva literatura, caracterizada por esa misma tendencia a reflexionar sobre el hecho poético ${ }^{4}$, a veces en busca de nuevos cauces, a veces como simple declaración de principios.

3. Entre las críticas más duras que cosechó caben citarse las de F. Navarro Ledesma, uno de los responsables del periódico satírico Gedeón, que le dedicó una serie de cinco artículos titulados «Batir de alas» (1897), en los que le ataca como persona, como escritor y, sobre todo, como crítico.

4. Estamos aún en 1893. A principios de siglo abundan los artículos de reflexión sobre el hecho literario: Juan Ramón Jiménez, Rubén Darío, Martínez Sierra, Benavente, Manuel Machado... plasman sus reflexiones estéticas en artículos específicos o aprovechan para insertarlas en artículos de crítica literaria. La revista Helios ofrece un buen muestrario de este tipo de reflexiones metaliterarias. 
La incipiente labor crítica de Rueda, favorable a Rubén Darío, le da pie a Clarín para explayarse en un juicio contra el poeta modernista, en el que utiliza sus recursos más belicosos. Comienza con un insulto directo a los «poetas americanos, como Rubén Darío, que no son más que sinsontes vestidos con plumaje pseudo-parisién» (Clarín, 1893b: 3), y sigue en la línea de la crítica satírica, ironizando y parodiando verso a verso un soneto de Darío.

En este texto pueden leerse, en boca de Clarín y en la temprana fecha de 1894, los reproches que luego se convertirán en tópicos en la crítica antimodernista: «la falta de respeto a la tradición artística y a la autoridad estética», el «mal gusto», el afrancesamiento y «el prurito reformista». Termina Clarín poniendo de manifiesto que, en realidad, su crítica y su preocupación por los extravíos de Rueda delatan la lectura atenta que él ha hecho de toda su obra $y$, por tanto, el reconocimiento implícito de su ingenio. El tono paternalista vuelve a imponerse, suavizando la crítica precedente. Aunque Clarín había subtitulado su artículo sobre Rueda «Fragmentos de una semblanza», resulta difícil recomponer la semblanza de Rueda, no sólo por el fragmentarismo, sino sobre todo por las excesivas digresiones que nos alejan del verdadero protagonista. No queda muy bien parado un escritor que ha sido retratado como persona fácilmente influenciable, crítico parcial, poeta poco sincero («es colorista y se entusiasma con Andalucía porque se lo ha propuesto») y escritor dominado por el prurito reformista.

Tras comparar estos dos artículos críticos escritos por Clarín, puede comprobarse que la objetividad del crítico queda condicionada por el grado de simpatía que le inspire el retratado. Despiertan en él este sentimiento los autores humildes, trabajadores honestos y deseosos de dar al gran público lo que éste le pide. Si algo no soporta Clarín es la actitud pretenciosa. Por eso a Rueda no le perdona que se dé aires de moderno, que se ponga a teorizar sobre el arte y que defienda a los que tienen como objetivo hacer un «arte original y superior».

Respecto a la literatura modernista, Clarín se mostró absolutamente contrario a ella, aunque su temprana muerte en 1901 le impidió conocer las grandes obras modernistas que se publican a partir de 1902. El reproche más frecuente que hace a los jóvenes es su falta de respeto a la tradición española y su dependencia de la moda francesa. Como hemos visto, se refiere a «ciertos poetas americanos como Rubén Darío, que no son más que sinsontes vestidos con plumaje pseudo parisién» (1893b). El mismo reproche de afrancesamiento le dirige a Valle-Inclán (1897b). También censura el sensualismo descarado de la joven literatura, sensualismo que para él raya la inmoralidad. Pero cuando sus críticas van dirigidas a autores concretos, sus ataques se matizan y 
adopta un tono condescendiente y paternalista, al considerar los excesos como una especie de sarampión juvenil que pasará con la edad. Lo más frecuente es que Clarín en sus críticas, convertido en consejero, se otorgue a sí mismo la misión de señalar a los jóvenes la dirección correcta por la que deben avanzar. Esto puede comprobarse en el matizado elogio que hace a las Odas de Eduardo Marquina (1900) y en su crítica a Martínez Ruiz (1897a), del que dice:

Martínez Ruiz es un anarquista literario; sus doctrinas son terribles; pero él es un mozo listo, listo de veras. Entre las pocas cosas que respeta está el castellano: escribe con corrección y facilidad [...] También está mal este joven despierto y muy ilustrado con la familia, según es, y con el cristianismo, etc., etc. [...] Pero no me asustan estas ideas. He visto el retrato de Martínez Ruiz; es casi un niño. [...] Pasará el sarampión que acaso es salud y quedará un escritor original, independiente... (1897a: 190).

La compleja relación entre Clarín y Azorín ha sido estudiada por Martínez Cachero (1953).

Una tercera modalidad crítica, dentro de la que plantea un enfoque objetivo, es la que podemos llamar crítica interpretativa: tiene cómo objeto orientar al gran público entre la gran cantidad de libros que se publican para que pueda elegir sus lecturas. Trata de explicar el sentido de una obra, su tema, sus valores explícitos e implícitos, para facilitar su comprensión, su aprecio y el goce estético derivado de la lectura. No suele descender a aspectos formales concretos, salvo que sean muy significativos, pero sí tiene en cuenta el estilo propio del autor. Además de analizar aspectos temáticos y estilísticos, el crítico puede auxiliarse de otros datos extrínsecos, como la biografía o la personalidad del autor, siempre en relación a la obra concreta y con el fin de facilitar su comprensión. Hay también una voluntad taxonómica, en el sentido de que se trata de clasificar una obra dentro de una tendencia y trazar un panorama literario del momento.

El enfoque de este tipo de crítica es objetivo, pero el crítico abandona toda actitud dogmática; no se siente un censor, sino un lector privilegiado, que quiere orientar a otros menos avispados. Tampoco emite juicios categóricos; sus valoraciones suelen ser matizadas y las críticas constructivas.

Muchos autores podrían incluirse dentro de esta tendencia, pero sin duda la figura clave es Eduardo Gómez de Baquero (firmó también con el seudónimo de Andrenio), que colaboró en La España Moderna, Los Lunes de El Imparcial, La Época, Nuevo Mundo... Fue un autor muy leído y gozó de respeto y admiración bastante generalizados. Sus críticas a los escritores modernistas muestran su buen criterio y su frecuente acierto en la valoración realizada pues, en general, sus máximos elogios se orientaron a los autores que luego la crítica reconoció unánimemente. Las reseñas de Gómez de Baquero pueden 
ser hoy un magnífico corpus textual en la revisión del canon finisecular. Cito como ejemplo de su buen hacer crítico y de su imparcialidad una de sus «Crónicas literarias», en La España Moderna, subtitulada «De la poesía lírica.- Poetas modernistas y no modernistas.- Alma, por D. Manuel Machado.- El alto de los bohemios, por D. Francisco Villaespesa.-Ninfeas y Almas de violeta, por D. Juan R. Jiménez [...]» (Gómez de Baquero, 1902). En ella, primero aborda la caracterización de la poesía modernista, en general, para pasar después a analizar las obras que figuran en el subtítulo. Gómez de Baquero pide primero prudencia a la hora de juzgar a la denostada corriente y pide paciencia, pues se necesita cierta perspectiva temporal para juzgar a un autor. Reconoce como primera característica de los modernistas su «afición a la originalidad», que puede derivar en extravagancia, que es la que les procura las burlas de lectores y críticos. Pero Gómez de Baquero reconoce que esta tendencia «tiene aspiraciones estéticas que merecen otra consideración que las burlas del ridículo» (1902: 169). Considera también que es difícil definir el Modernismo, pues «las escuelas modernas suelen ser poco dogmáticas y con frecuencia encierran elementos contradictorios» (1902: 169). Y se atreve a dar dos características generales de la poesía modernista: la renovación formal y el intento de «remozar el fondo psicológico de la poesía» pues «las variaciones históricas de los sentimientos e ideas permiten que en cada época pueda el poeta encontrar acentos nuevos para cantar cosas en esencia eternas» (1902: 169). La imparcialidad de Gómez de Baquero se ve cuando comenta los distintos derroteros por los que puede transcurrir ese remozamiento de los sentimientos eternos:

No deja de ser resbaladizo este terreno de la nueva psiquis y es muy explicable que algunos de los modernistas se deslicen en sus psicologicismos, dando por refinamientos espirituales solemnes boberías, empeñándose en idealizar lo feo y repugnante o cayendo en tal vaguedad que apenas se les entiende. Sin embargo en la poesía hay que admitir cierta vaguedad. Su asunto principal es el sentimiento, y como las raíces del sentimiento penetran en la parte inconsciente de nuestro ser, siempre hay en él algo de vago e inefable. (1902: 169-170).

Después de la caracterización general, Gómez de Baquero aborda la crítica de varios libros poéticos recién publicados. Puede servir la referida a El alto de los bohemios de Francisco Villaespesa para ver el buen criterio, la fundamentación de la valoración que hace y su imparcialidad: «Hay delicadeza de sentimiento, notas de suave y melancólica ternura y felices imágenes en estas composiciones. Sus principales defectos son la exageración y la extravagancia» (1902: 174); y, después de comentar algunos poemas, concluye: «El Sr. Villaespesa es un poeta que tiene personalidad. Algunas de sus composiciones 
llevan cierto sello patricio que las hace muy agradables y en todas huye de la vulgaridad. Cuando corrija algunas exageraciones y se acostumbre a limar un poco los versos, sus composiciones serán mucho más bellas» (1902: 175).

También Emilia Pardo Bazán puede enmarcarse dentro de esta tendencia, de crítica objetiva interpretativa. Al margen de sus controvertidos artículos sobre el Naturalismo, estuvo muy atenta a la nueva literatura y se mostró favorable a los modernistas en un artículo titulado «La nueva generación de novelistas y cuentistas en España» (1904: 257-270). En él, reconoce, como características generales de las nuevas promociones, el pesimismo -imbuido a veces de misticismo-, el neorromanticismo y, junto a elementos extranjeros, el fondo nacional y regional. Tras un recorrido por varios autores representativos del modernismo, destaca a Martínez Ruiz, Pío Baroja y Llanas Aguilaniedo, los tres finamente leídos y también elogiados por ella, con quienes -dice- «estamos de lleno en la corriente modernista, que aquí como en todas partes, ha inspirado chanzas y sátiras a la prensa» (Pardo Bazán, 1904: 270).

Algunos autores que pueden enmarcarse dentro de la crítica objetiva-interpretativa hacen en ocasiones un cierto alarde de erudición, con un prurito científico. Es el caso de Emilio Bobadilla, «Fray Candil», que hace un uso reiterado de referencias a ciencias diversas, terminología más especializada y citas a autoridades en la materia. A menudo las múltiples alusiones y referencias evidencian un eclecticismo excesivo, al servirse de ciencias muy diversas, como la antropología criminal, la crítica sociológica, la psicología..., que ponen de relieve un conocimiento y una asimilación superficiales. Pero lo más curioso es que «Fray Candil» combina este alarde de erudición, muestra incuestionable de objetividad, con ataques satíricos, que derivan a veces en el insulto personal. La actitud desinteresada de la crítica objetiva, pretendidamente científica, se traiciona así con el subjetivismo y parcialismo que conlleva la sátira. Copio un fragmento de este tipo de crítica:

Lo que caracteriza a Núñez de Arce es la fuerza plástica. Sus versos invitan a pasarles los dedos como si tuvieran relieve. Dentro de este cincelador esmerado se oculta un creyente que en vano se lamenta de que la duda le persigue. La duda de Núñez de Arce -me adhiero a la opinión de Menéndez Pelayotiene mucho de literaria. Núñez de Arce se burla de Darwin, quizá sin haberle leído, maldice, en nombre de Dios, de Voltaire y de la ciencia contemporánea; pero cree en la otra vida y en... Sagasta. No veo la duda, ni con cien leguas. Tal vez la duda del gran lírico surja de la misma creencia» («Fray Candil», 1892: 157).

Distinto es el caso de Andrés González Blanco, al que también le gusta apoyarse en autoridades y fundamentar sus valoraciones en conocimientos amplios y diversos, pero lo hace con mayor rigor y conocimiento de causa. 
Publicó reseñas y artículos diversos en revistas como La República de las Letras, Nuestro Tiempo, Renacimiento..., y recogió muchos de sus artículos en la serie Los contemporáneos (1907, 1910 y 1912). Podíamos denominar este tipo de crítica reflexiva-erudita: frecuentemente su atención a una obra concreta deriva en reflexión personal sobre cuestiones estéticas de su interés, con lo que tiene puntos de contacto con la crítica subjetiva. A menudo se centra en aspectos parciales de la obra y de su interés particular, para elucubrar sobre esa cuestión concreta, sin abordar una aproximación general a la obra reseñada. Por otra parte, Andrés González Blanco se permite seleccionar la obra objeto de atención exclusivamente por su gusto particular. No es un tipo de crítica que pueda servir de orientación al gran público. El afán de erudición, que le lleva a un exceso de citas, a menudo en diversos idiomas (latín, griego, inglés, francés, alemán, italiano), así como la referencia a las teorías críticas del momento, orienta este tipo de crítica hacia un lector cualificado. Seguramente A. González Blanco dirigía sus eruditas reflexiones críticas hacia otros escritores que compartían sus mismas inquietudes estéticas. Tal como ha estudiado Martínez Cachero (1963), a pesar de los defectos de su críticas - «citas, divagaciones, fárrago, desorden, benevolencia demasiado generosa» (1963: 119)-, muestra enorme sensibilidad, amplia información, medios instrumentales..., con lo que sus críticas pueden servir bien para dar una idea de las inquietudes estéticas suyas y de sus «contemporáneos».

Ese mismo interés es el que puede ofrecer la crítica declaradamente subjetiva, la que en general practicaron los escritores modernistas. Frente a los partidarios de la crítica objetiva, la nueva generación era consciente de que el arte ha de ser captado por la intuición, por la sensibilidad, no por la razón; de que no hay valores absolutos a los que adecuar un juicio de valor; de que las normas (métricas, gramaticales, retóricas...- constriñen más que ayudan; de que la creación tiene su razón de ser en sí misma y puede tener la función de educar la sensibilidad y crear conciencia, pero nunca la de dirigir por los caminos de una verdad y una moral que una parte de la sociedad quiere imponer; de que la obra literaria no es una obra científica y, por tanto, no se le puede aplicar el método analítico.

Partidarios de un arte de sugerencias, la crítica que se plantean consiste en clarificar esa riqueza de sugerencia que contiene la obra reseñada. Se trata de hacer explícitos los valores de una obra que, gracias a la exquisita sensibilidad del crítico-poeta, el lector puede apreciar y gozar igualmente. Más que explicar, el crítico recrea el efecto que le ha producido la lectura de la obra reseñada. Pero hay más: convertida también la obra en motivo de goce y de reflexión estéticos, el crítico-poeta recrea la obra; es decir, el resultado de su 
acción crítica es una nueva creación que se ofrece al lector como tal. La creación literaria es punto de partida y punto de llegada, pues muchos de estos textos son ejemplos de prosa poética. En casos extremos, la obra criticada es casi sólo un pretexto para comunicar la propia experiencia, para comunicar sus impresiones y hacerlo creando un nuevo texto artístico.

El crítico es un poeta que no se dedica profesionalmente a la crítica, sino que la aborda sólo ocasionalmente. Éste es el tipo de crítica que realizan a principios de siglo autores como Juan Ramón Jiménez, Ramón Pérez de Ayala o Manuel Machado, casi siempre en revistas en cuya edición participan activamente. En otro lugar he estudiado con mayor detalle el caso concreto de Juan Ramón Jiménez (Celma, 1991b). Recordaré ahora un artículo que puede servir muy bien para ejemplificar este tipo de crítica, es el titulado «La aldea lejana. Con motivo de La aldea perdida», de Ramón Pérez de Ayala. El subtítulo pone en evidencia la orientación del artículo: la lectura de La aldea perdida de Armando Palacio Valdés es sólo un motivo o pretexto para hacer una lectura personal, reflexionar sobre la naturaleza y el arte y crear un nuevo texto que tiene indudables valores literarios. El comienzo de la lectura que hace Pérez de Ayala de la obra de Palacio Valdés es suficientemente elocuente a este respecto:

Cuando atardece en el cielo, hay tristeza crepuscular en las almas.

El balcón encuadra un espacio luminoso, en donde se recorta la silueta azulada y dura de la ciudad sobre el aliento rojo de la tarde que fenece.

El silencio de mi estancia va poblándose de formas impalpables que se agrupan en los ángulos sombríos -son fantasmas incógnitos que evocan el ensueño de un bebedor de haschichs. Hay músicas sutiles y lejanas que hacen vibrar el aire (1903: 5).

La valoración de la obra reseñada está implícita y depende del mayor o menor número de sugerencias que procure. En este caso, se suceden una serie de sensaciones, impresiones sensoriales, recuerdos..., que conducen a una valoración final hiperbólicamente positiva: «Es un poema homérico lleno de dulzura, de armonía, de grandeza heroica y de paz aldeana» (1903: 14).

El valor de la crítica impresionista como fuente historiográfica es muy diferente del que tiene la crítica objetiva. Intentar reconstruir la realidad histórico-literaria del Fin de siglo, a partir de artículos de esta modalidad, daría un escaso rendimiento, por varias razones. Hay que partir de la base de la selección absolutamente personal, acorde con la propia ideología y estética, que realiza el crítico. No pretender trazar un esbozo general de la producción literaria de su momento, sino que busca recrear la impresión que una obra le ha producido a él y, a lo sumo, trasmitirla y hacer partícipes de ella a los lectores. Dado que el crítico es también escritor, siempre hay una voluntad 
de estilo en su texto, una voluntad de recreación literaria. Pero, a menudo, la obra base es un motivo para la reflexión estética y, por tanto, los artículos de crítica subjetiva, impresionista, permiten conocer de primera mano la concepción estética del crítico, que es otro escritor, y la percepción que un lector privilegiado tiene de la poética del autor reseñado.

En suma, la crítica literaria publicada en las revistas del Fin de siglo constituye una fuente para la reconstrucción historiográfica de su momento. No puede ser, obviamente, la única fuente ni puede sustituir los análisis del crítico actual, que conoce ya el canon relativo a esa época y que puede servirse de herramientas y de métodos de análisis modernos y fiables. El crítico del Fin de siglo necesitaba un distanciamiento, una perspectiva temporal -como reconocía Gómez de Baquero- para ver el conjunto y la evolución de los autores, perspectiva temporal que él no tenía y sí tiene el estudioso actual. Pero los historiadores literarios actuales también necesitan de la perspectiva de los lectores cualificados que eran los críticos del momento, pues sus reseñas nos revelan aspectos contextuales olvidados, apreciaciones estéticas nacidas del clima literario que se vivía en ese momento. Ambas perspectivas se muestran complementarias y puede afirmarse que ha sido esta complementariedad la que ha permitido liberar a la literatura de la época de muchos tópicos y tergiversaciones. El Modernismo visto por los modernistas nos ha abierto los ojos a los estudiosos y lectores del Fin de siglo español.

Valladolid, 11 de mayo de 2014

\section{Bibliografía citada}

ALAS, Leopoldo «Clarín», «Revista literaria. La crítica y la poesía en España», en La España Moderna, 13 (1890), 193-216.

— «Vivos y muertos», en Madrid Cómico, 529 (1893a), 3.

— «Vivos y muertos», en Madrid Cómico, 566 (1893b), 3.

— «Palique», Madrid Cómico, 742 (1897a), 190.

— «Palique», en Madrid Cómico, 762 (1897b), 315.

— «Palique», Madrid Cómico, 19 (1900), 150.

Azorín (José Martínez Ruiz). «Somos iconoclastas», en Alma Española, 10 (1904), $15-16$.

ANÓNIMO, «Clarindustrial», en Revista Nueva, II, 2. ${ }^{a}$ serie, 26 (1899) 120-21.

BESER, Sergio, Leopoldo Alas, crítico literario, Madrid, Gredos, 1968.

«FRAY CANDIL»[Emilio Bobadilla], Triquitraques, Madrid, Librería de Fernando $\mathrm{Fe}, 1892$.

Celma Valero, María Pilar, La pluma ante el espejo (Visión autocrítica del Fin de siglo), Universidad de Salamanca, 1989a. 
- La crítica de actualidad en el Fin de siglo (Estudio y textos), Salamanca, Plaza Universitaria, 1989b.

- Literatura y periodismo en las revistas del Fin de siglo. Estudio e índices, Gijón, Júcar, 1991a.

— «Crítica y poética del primer Juan Ramón» en Juan Ramón Jiménez. Poesía total y obra en marcha, Universidad de Málaga-Anthropos, 1991b, pp. 375-385.

GÓMEZ DE BAQUERO, Eduardo, «Crónica literaria. De la poesía lírica.- Poetas modernistas y no modernistas.- Alma, por D. Manuel Machado.- El alto de los bohemios, por D. Francisco Villaespesa.-Ninfeas y Almas de violeta, por D. Juan R. Jiménez [...]», en La España Moderna, 159 (1902), 166-176.

GULLón, Ricardo, El modernismo visto por los modernistas, Madrid, Guadarrama, 1980.

MARTínez CAhero, José María, «Clarín y Azorín (una amistad y un fervor)», Archivum, III, 2 (1953), 159-180.

- Andrés González Blanco: una vida para la literatura, Oviedo, Instituto de Estudios Asturianos, 1963.

— «La actitud antimodernista del crítico Clarín», ALEUA, 2 (1983), 383-398.

NAVARRO LedeSmA, Francisco, «Batir de alas», en Gedeón, 69, 70, 72, 73 y 76 (1897), s.p.

PARDO BAZÁN, Emilia, «La nueva generación de novelistas y cuentistas en España», en Helios, 12 (1904), 257-270.

PÉREZ DE AYALA, Ramón, «La aldea lejana. Con motivo de La aldea perdida», en Helios, 1 (1903), 5-14.

RiBBANS, Geoffrey, «Riqueza inagotada de las revistas literarias modernas», Revista de Literatura, XIII (1958), pp. 30-49.

RODRíGUEZ MORANTA, Inmaculada, La revista Renacimiento (1907): una contribución al programa ético y estético del Modernismo hispánico, Vigo, Editorial Academia del Hispanismo, Biblioteca Canon, 2012.

SERRANO AlONSO, Javier y Amparo de Juan Bolufer, Literatura hispánica y prensa periódica (1875-1931). Actas del Congreso Internacional celebrado en Lugo en noviembre de 2008, Santiago de Compostela, Universidade de Santiago de Compostela, 2009.

SOBEJANO, Gonzalo, «Clarín y la crisis de la crítica satírica», en Forma literaria y sensibilidad social, Madrid, Gredos, 1967.

Fecha de recepción: 15/09/2014

Fecha de aceptación: 15/10/2014 